\title{
Role of nanoadditive blended biodiesel emulsion fuel on the performance and emission characteristics of diesel engine
}

\author{
S. Rajesh kumar $^{1 *}$ P. Sai chaitanya ${ }^{2 *}$ \\ ${ }^{1}$ Department of mechanical engineering, GIET Engineering College, \\ Rajmundry, 533101, A.P, India. \\ ${ }^{2} \mathrm{JTS}$, Department of mechanical engineering, Indian Institute of Technology, \\ Tirupati, A.P, India \\ *E-mail: rk44961@gmail.com¹ chaitanya@iittp.ac.in²
}

\begin{abstract}
An investigational research is carried out to found the performance and emission characteristics of a direct injection (DI) diesel engine with aluminium oxide nanoparticle additives in water and biodiesel blend. Palm methyl ester was produced by transesterification and blended with water. Aluminium oxide nanoparticles of 50 and $100 \mathrm{ppm}$ in proportion are subjected to high-speed mechanical agitation followed by ultrasonication. The experimentations were conducted on a single cylinder DI diesel engine at a constant speed of $1500 \mathrm{rpm}$ using different aluminium-oxide $\left(\mathrm{AL}_{2} \mathrm{O}_{3}\right)$-blended with emulsified biodiesel (PBD5\%W+100ppm, PBD10\%W+50ppm, PBD15\%W+100ppm, PBD20\%W+50ppm) and the outcomes were compared with those of neat diesel and Palm biodiesel. The experimental results indicated that brake thermal efficiency of PBD20\%W+50 ppm and PBD $+15 \% \mathrm{~W}+100 \mathrm{ppm}$ aluminium oxide was increased by $3-4 \%$ with $1.72 \%$ betterment in specific fuel consumption. Emissions of nitrogen oxide and hydrocarbon were reasonably lower than diesel fuel.
\end{abstract}

Keywords: Bio diesel; emulsification; surfactants; diesel engine; emissions.

\section{INTRODUCTION}

Faster depletion of fossil fuels and strict emission regulations drive the researchers to search for alternative fuels for diesel engines. Efforts have been made to use straight vegetable oils as fuel in diesel engines. But higher viscosity of vegetable oil restricts its direct use in diesel engines. So the vegetable oils are converted in to biodiesel using transesterification process. Biodiesel is a renewable energy, which is considered the most viable alternative for replacement of mineral diesel fuel in compression ignition engines [1, 2]. It is a biodegradable fuel comprised of fatty acid methyl ester and synthesized from the transesterification of vegetable oil or animal fats [3]. The world currently mandates biodiesel usage based mostly on blending with diesel fuel. These blends are designated according to the biodiesel blending volumetric percentage, where B100 represents 100\% biodiesel, B20 indicates $20 \%$ biodiesel and B30 indicates 30\% biodiesel, depending on the volumetric percentage [4]. Palm oil is derived from a plant that is perennial and grows in tropical regions, 
especially humid lowlands. In general, palm oil has the highest oil yield compared to other common biodiesel feed stock; as a comparison, production is about thirteen times higher than that of soybean [5]. It very well may be finished up from the examination that the fuel properties of palm biodiesel have affected the majority of the ignition parameters, psychochemical properties and higher oxygen content [6,7]. The reduction in emissions accomplished by appropriately planned diesel-water emulsification is universal regardless of engine. The essential advantage of water-diesel emulsions in diesel engines is a prominent decrease in $\mathrm{NO}_{\mathrm{x}}$ emissions [8], Nano-added substance mix reduced peak pressure heat release rate and ignition delay as compared to neat diesel, it was likewise revealed that there was lessening in $\mathrm{NO}_{\mathrm{x}}$ and smoke emissions with emulsified fuel [9]. The adding of water as emulsion improved combustion efficiency. It was found that brake power, engine power and also the engine torque were enhanced with the emulsified powers for both diesel and benzene till expansion of $25 \%$ water. Adding water to diesel-benzene could reduce bad emissions of the vehicles $[10,11]$.

The emulsion technique had higher capability of synchronous lessening of $\mathrm{NO}_{\mathrm{x}}$ and smoke outflow at all loads than water injection method. In any case, $\mathrm{CO}$ and $\mathrm{HC}$ levels were higher with emulsion than water infusion [12]. Discharges of $\mathrm{NO}_{\mathrm{x}}$ and $\mathrm{PM}$ diminished up to $30 \%$ and $60 \%$, individually though hydrocarbons and carbon monoxide increased with increasing $\mathrm{s}$ water content in the emulsion. The combustion efficiency was enhanced when water was emulsified with diesel up to $15 \%$ [13]. The combustion began before for biodiesel and its blends compared to diesel [14]. The peak cylinder pressure of biodiesel and its blends was found to be higher than that of diesel fuel at lower loads and almost identical at higher engine loads. The peak pressure rise rate and peak heat release rate for biodiesel were higher than those for diesel fuel at lower engine loads, but were lower at higher engine loads [15]. The vegetable oil ordinarily contains free fatty acids, water, high viscosity and poor volatility, some techniques to overcome these troubles are Preheating, Blending, Micro emulsion, Pyrolysis (Thermal breaking), transesterification. The area describes the execution parameter BTE and BSFC of biodiesel gotten from a few vegetable oils. Additionally, discharge parameters like carbon monoxide $(\mathrm{CO})$, hydrocarbon $(\mathrm{HC})$, nitrogen oxide $\left(\mathrm{NO}_{\mathrm{x}}\right)$, and smoke thickness of different biodiesel mixes have been watched [16]. The functional groups in the emulsifiers, bio-oils, and diesel are dissected by a Fourier transform infrared spectroscopy (FTIR) to recognize the qualities of emulsions. Where three commercial Emulsifiers (i.e., Span 80, Tween 80, and Atlox 4914) and the bio-oils created from the quick pyrolysis of wood squanders were utilized. The outcomes propose that Atlox 4914 gives the best execution compared with Span 80 and Tween 80. The relationship of ideal HLB and HHV gives the best outcome [17]. The emulsification innovation has been considered to lessen the NOx emanation level of fuel. The surfactants (span80 and tween80) add for an appropriate blending of w/o and o/w/o emulsions. The impacts of the emulsification factors, for example, hydrophilic-lipophilic adjust (HLB), and water content on the fuel properties and emulsion qualities of $\mathrm{W} / \mathrm{O}$ and $\mathrm{O} / \mathrm{W} / \mathrm{O}$ emulsions were examined. The trial comes about demonstrate that the surfactant blend with HLB $=13$ delivered the most astounding emulsification dependability while HLB $=6$ created the least emulsification stability [18]. The presence of oxygen in the soybean biodiesel, and the better blending abilities of the nanoparticles, diminish the $\mathrm{CO}$ and unburned $\mathrm{HC}$ considerably, however there is a little increment in NOx at full load condition [19]. The distinctive qualities of the molecule agglomerates are responsible for the different micro explosion behaviour that was observed 
[20]. Significant decrease was also observed in level of pollutants in emissions using nanoparticles. Characterization of $\mathrm{AlO}(\mathrm{OH})$ nanoparticles utilising XRD and TEM was analyzed [21]. This study aims to characterize the emulsified biodiesel fuel properties for its application in diesel engine and to conduct the experimental investigation without modifying the engine settings such as injection timing, injection pressure, and compression ratio. Moreover, experiments with biodiesel, diesel, Biodiesel with water emulsion by adding aluminium oxide nano particles are conducted.

\section{MATERIALS AND METHODS}

\section{Preparation of Biodiesel}

The raw Palm oil was extracted from the seeds of Palm fruit. The Figure 1 shows the (a). Palm fruit and Palm oil (b). The raw oil was procured from the local market and the biodiesel was prepared by transesterification process as shown in Figure 2.

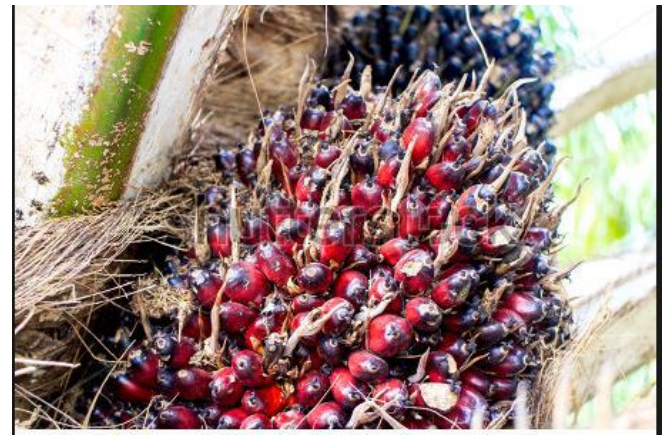

(a)

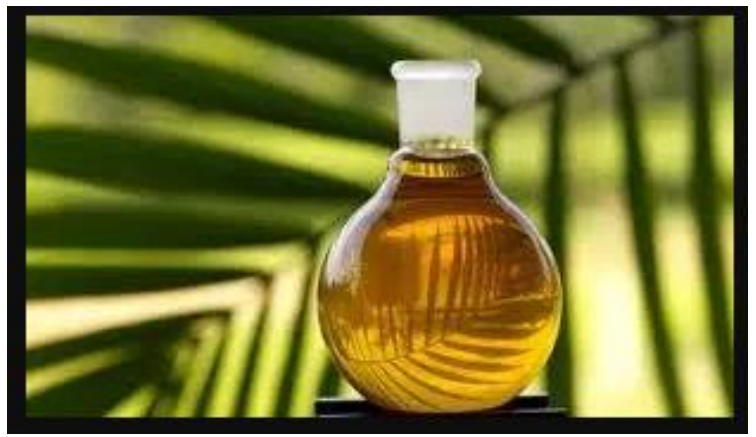

(b)

Figure 1. Palm fruit (a) and Palm oil (b).

\section{Methodology}

Biodiesel is prepared from palm oil using transesterification process. The steps that are carried out while preparing biodiesel using palm oil by transesterification process are as follows: First 1 litre of palm oil is poured in a pan and then heated up to a temperature of $60^{\circ} \mathrm{C}$. A beaker is filled with $200 \mathrm{ml}$ of methanol and then about $3.5 \mathrm{~g}$ of Sodium Hydroxide is added as a catalyst. The beaker is closed and then stirred for about half an hour and Sodium Methoxide is formed as a result. The heated oil is poured into a separate container and then the Sodium Methoxide solution is mixed along with the heated oil. The mixture is allowed to settle for about 12 hours and then the biodiesel is formed along with glycerine, deposited at the bottom. Finally, the biodiesel is separated from the container by using the separating funnel and then it is added in the definite proportions along with the water to be used for the experimental verifications by adding aluminium oxide. 


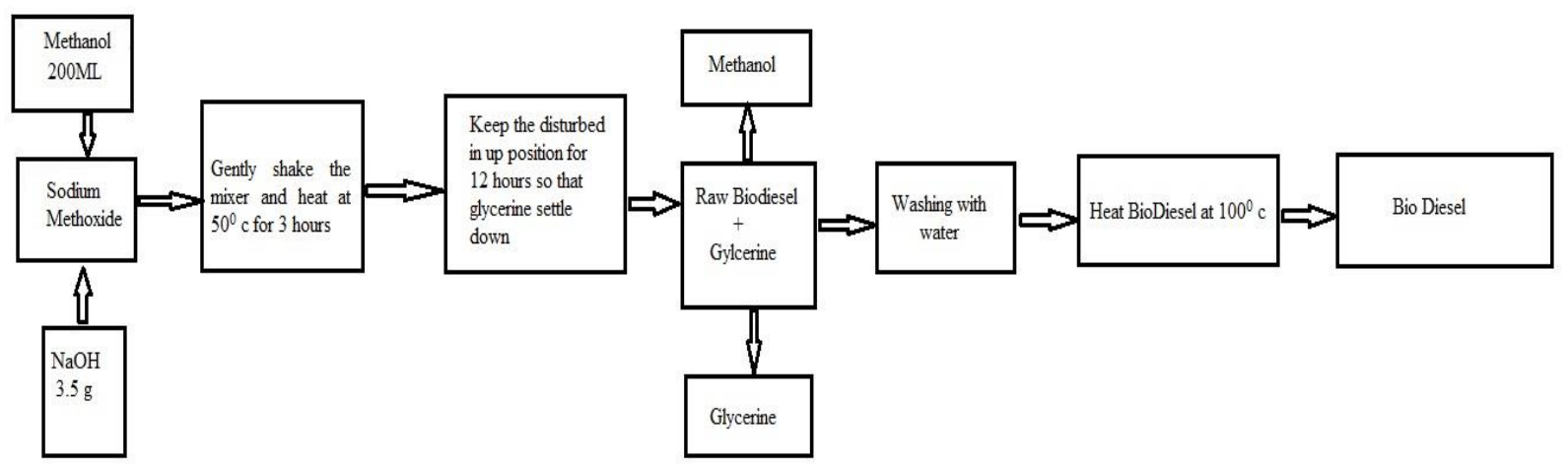

Figure 2. Transesterification process

\section{Preparation of Nano Particle Blended Emulsified Palm Blends}

The biodiesel emulsion fuel is prepared by emulsification technique comprising of palm biodiesel, $(5 \%, 10 \%, 15 \%, 20 \%)$ of water, and $2 \%$ of surfactants (Span80 and Tween 80$)$ with the aid of a mechanical agitator as shown in Figure 3. The prepared biodiesel emulsion fuel is mixed with the alumina nanoparticles in the mass fractions of $50 \mathrm{ppm}$ and $100 \mathrm{ppm}$ with the aid of ultrasonicator set at a frequency of $20 \mathrm{kHz}$ for $2 \mathrm{hr}$. The resulting fuel samples are termed as PBDS 5W100A, PBDS10W50A, PBDS15W100A, PBDS20W50A. The fuel samples are characterized and their properties are tabulated in Table 1.

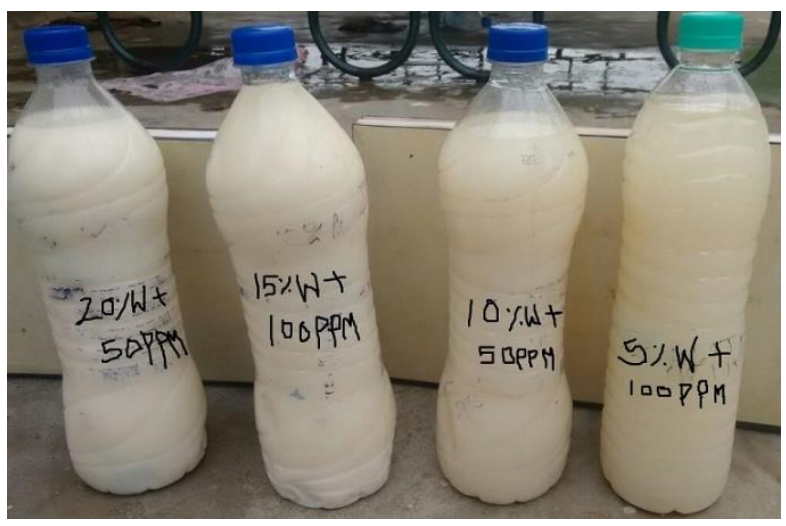

Figure 3. Emulsified biodiesel with different nano particles concentration 
Table 1. Properties of tested fuel samples

\begin{tabular}{lcccc}
\hline \multicolumn{1}{c}{ Fuel } & $\begin{array}{c}\text { Flash } \\
\text { Point }\left({ }^{0} \mathrm{C}\right)\end{array}$ & $\begin{array}{c}\text { Fire Point } \\
\left({ }^{0} \mathrm{C}\right)\end{array}$ & $\begin{array}{c}\text { Viscosity } \\
(\text { Centistokes })\end{array}$ & $\begin{array}{c}\text { Calorific } \\
\text { value }(\mathrm{kJ} / \mathrm{kg})\end{array}$ \\
\hline Diesel & 52 & 57 & 5.32 & 43000 \\
Bio diesel & 170 & 175 & 7.57 & 39900 \\
Emulsion1 & 168 & 172 & 7.23 & 39000 \\
$(5 \% \mathrm{w}+100 \mathrm{ppm})$ & & & & \\
Emulsion 2 & 170 & 174 & 7.9 & 37800 \\
$(10 \% w+50 \mathrm{ppm})$ & & & & 37500 \\
Emulsion 3 & 172 & 176 & 8.3 & 36700 \\
$(15 \% \mathrm{w}+100 \mathrm{ppm})$ & & & & \\
$\begin{array}{l}\text { Emulsion 4 } \\
(20 \% \mathrm{w}+50 \mathrm{ppm})\end{array}$ & 179 & 183 & 8.5 & \\
\hline
\end{tabular}

\section{Experimental Setup and Procedure}

In the investigational preparation, a single-cylinder, four-stroke, constant speed, watercooled, high-speed diesel engine with a rope brake dynamometer is used as shown in Figure 4. The specifications of the engine are given in Table 2. To measure the air consumption, an air box with small orifice is provided at the air inlet. A 5 Gas analyzer and smoke meter with smoke gun are used to analyse the exhaust gas and smoke, respectively.

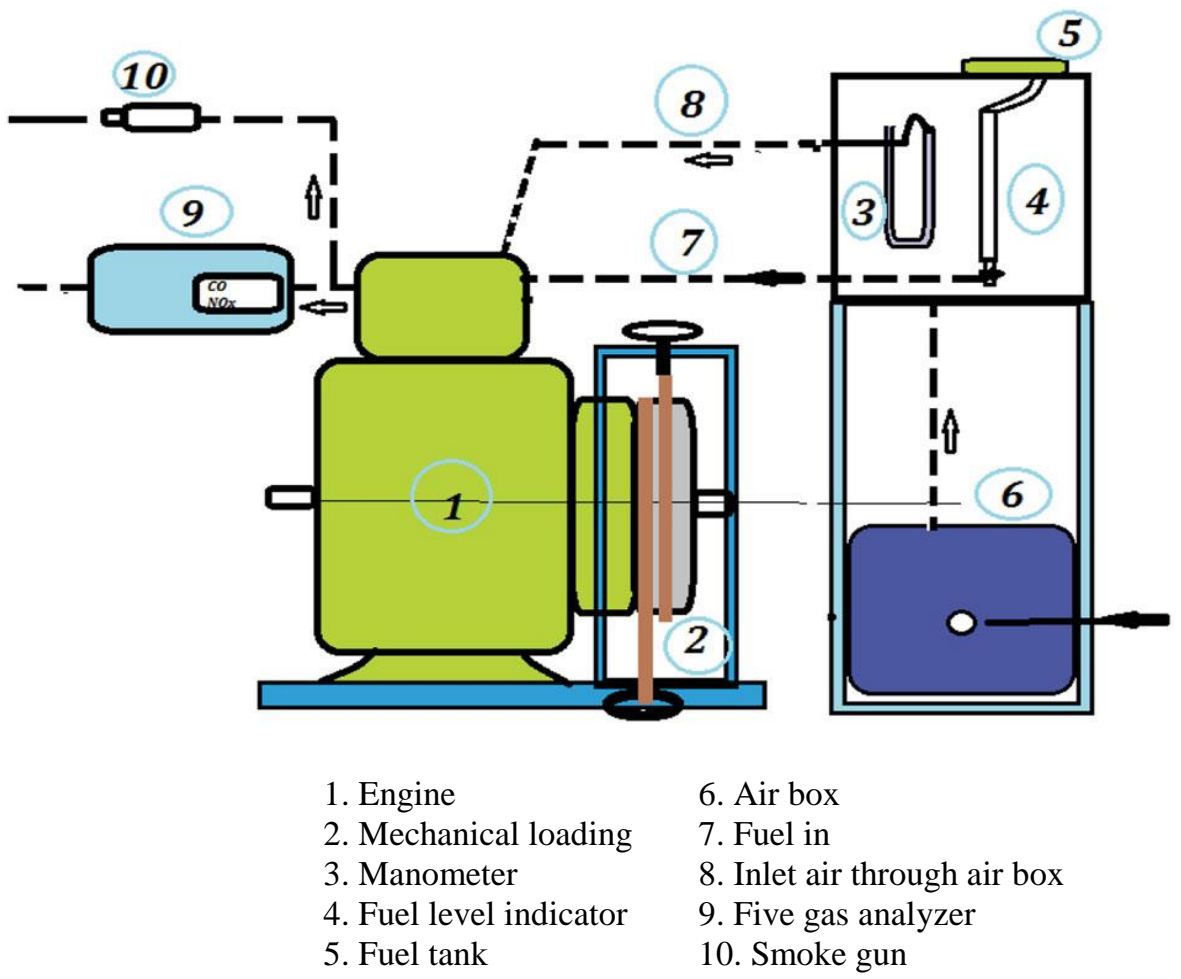

Figure 4: Schematic diagram of Experimental setup 
Table 2. Engine specifications.

\begin{tabular}{ll}
\hline Description & Specification \\
\hline Bore & $80 \mathrm{~mm}$ \\
Stroke & $110 \mathrm{~mm}$ \\
RPM & 1500 \\
BHP & $5 \mathrm{HP}$ SINGLECYLINDER) \\
Compression Ratio & $16.5: 1$ \\
Method of loading & Manual \\
Injection pressure (bar) & 200 \\
Make & Kirloskar AV-1 \\
\hline
\end{tabular}

\section{RESULTS AND DISCUSSION}

The experimental analysis on the performance and emission characteristics of a diesel engine with alumina-nano-added blends of emulsified Palm bio diesel is illustrated in this section.

\section{Performance and Characteristics}

The variation of BTE with respect to engine loads, for different emulsified bio diesel with nano additives blends of PME (PBD5\%W+100ppm, PBD10\%W+50ppm, $\mathrm{PBD} 15 \% \mathrm{~W}+100 \mathrm{ppm}, \mathrm{PBD} 20 \% \mathrm{~W}+50 \mathrm{ppm})$ is shown in Figure 5. The BTE was increased with the addition of Nano in all tested emulsified biodiesel blends compared to neat diesel. Because of the effect of micro-explosion of the water droplets contained in the emulsion fuel, which helps to break the larger size droplets oil into smaller one, accelerating fuel evaporation and mixing with air, thereby resulting in a faster combustion process and the higher BTE. The BTE is improved by 3 to $4 \%$ with $\mathrm{BD}+20 \% \mathrm{~W}+50 \mathrm{ppm}$ and $\mathrm{BD}+15 \% \mathrm{~W}+100 \mathrm{ppm}$ of $\mathrm{Al}_{2} \mathrm{O}_{3}$ because improved combustion characteristics and uniform burning $[19,20]$.

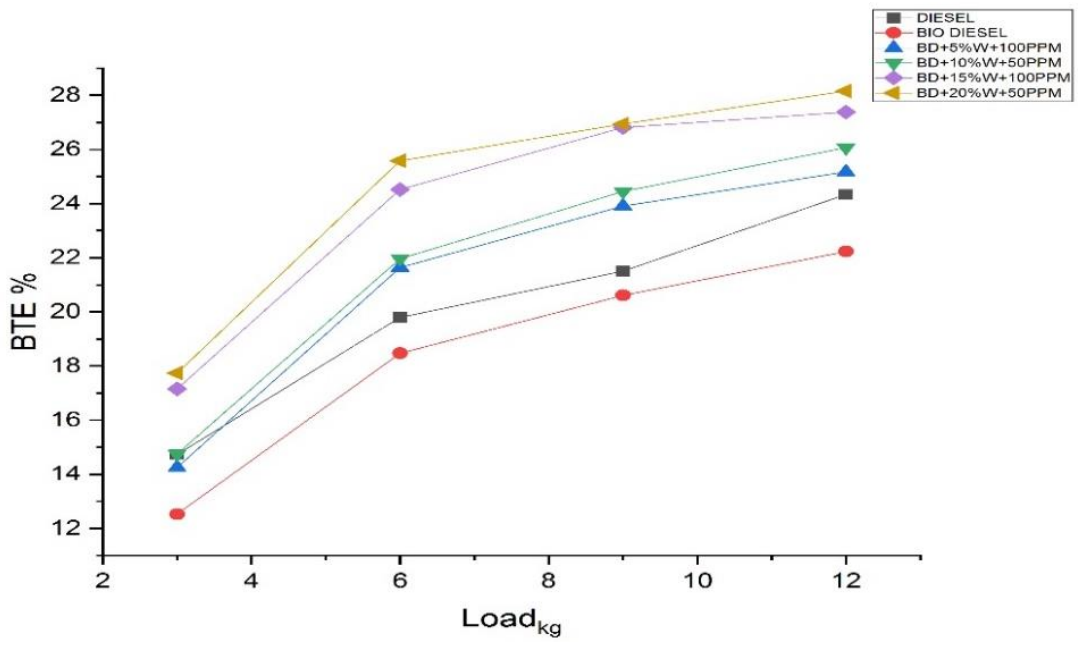

Figure 5. Load v/s BTE for Emulsified Bio diesel with nano additives 
Figure 6 shows the variation of BSFC with respect to engine loads, for different emulsified bio diesel with nano additives blends of PME (PBD5\%W+100ppm, PBD10\%W+50ppm, PBD15\%W+100ppm, PBD20\%W+50ppm) is shown in Figure 6. The BSFC was decreased with the addition of Nano in all tested emulsified biodiesel blends because of improved surface to volume ratio by the catalytic effect during the combustion. The BSFC for PBD+15\% W+100 ppm of aluminium oxide was lowest as $0.28 \mathrm{~kg} / \mathrm{kWh}$, which is $1 \%$ better than diesel. And also due to the presence of the alumina nano particle that increases the atomization rate and the large surface area, of the fuel leading to complete combustion $[19,20]$.

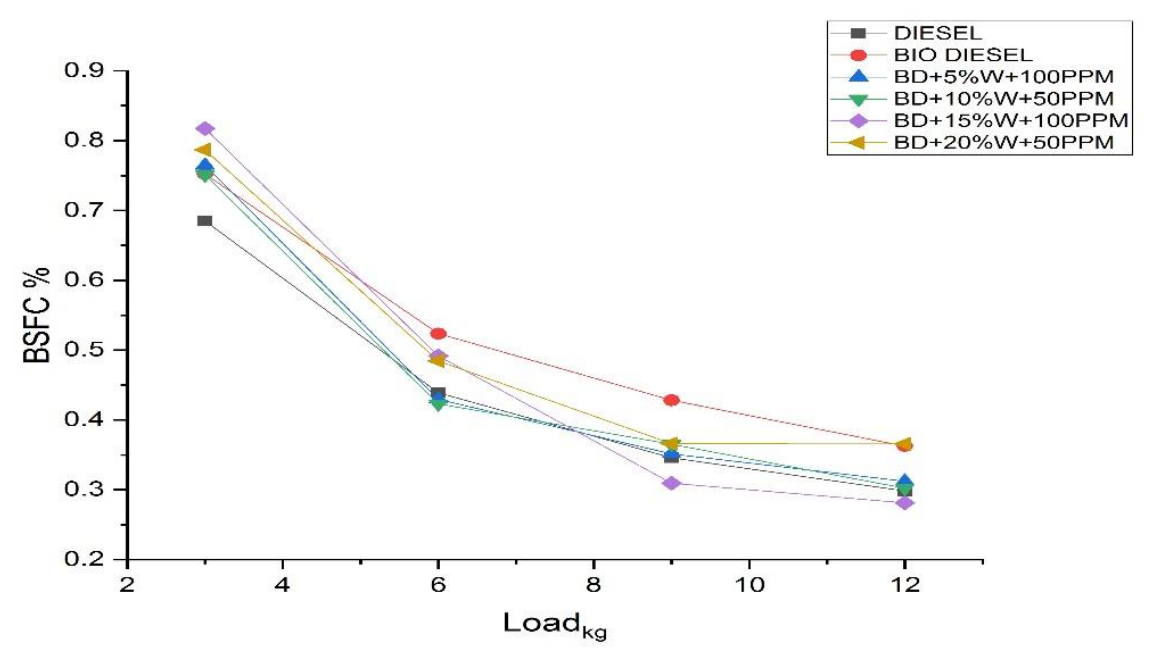

Figure 6. Load v/s SFC for emulsified bio diesel with Nano additives

\section{Emission Characteristics}

The disparity of NOx with respect to the load for the tested $\mathrm{Al}_{2} \mathrm{O}_{3}$ nano-added emulsified biodiesel blends is shown in Figure 7.

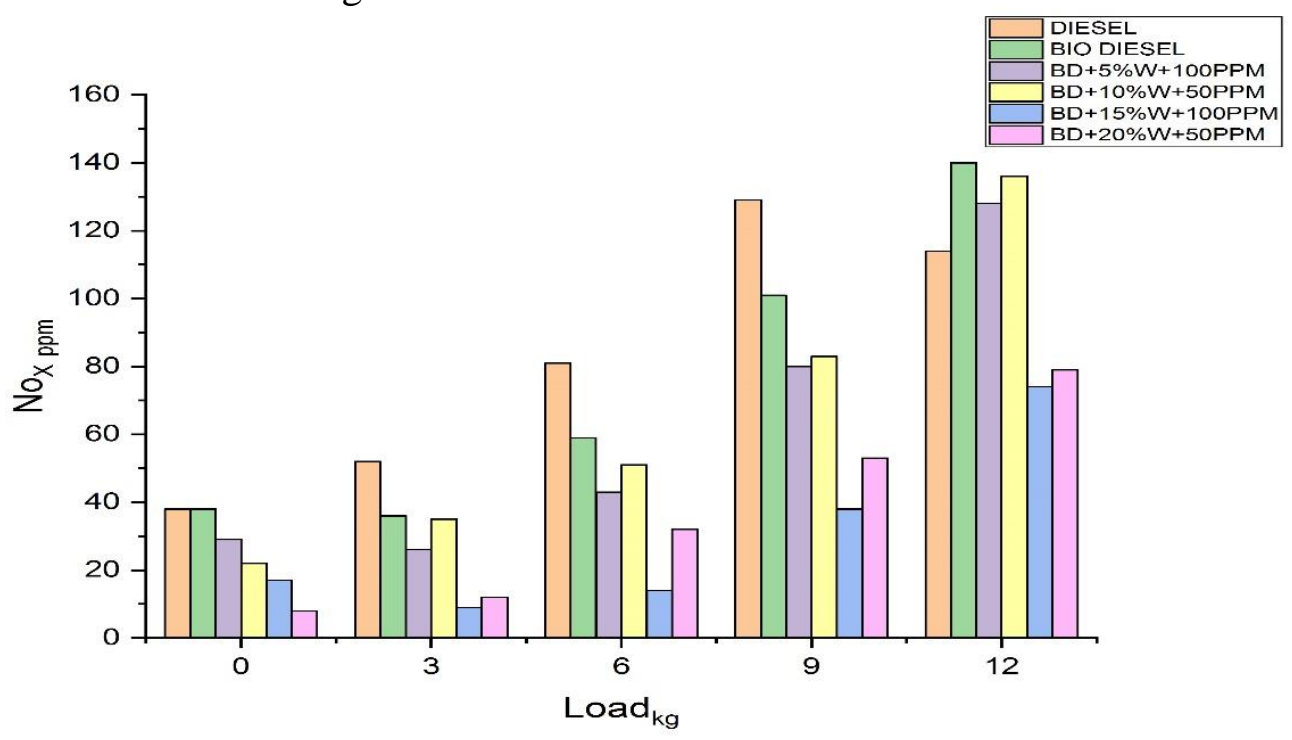

Figure 7. $\mathrm{NO}_{\mathrm{X}} \mathrm{Vs}$ Load for emulsified bio diesel addition of nano additives 
Formation of NOx mainly depends on higher temperature presents in the exhaust gas. The variation of NOx emission with engine load for diesel, PBD and PBD emulsions with nano additives are shown in fig. NOx formation $114 \mathrm{ppm}$ for full load condition while operating with diesel. PBD Produces $140 \mathrm{ppm}$ of NOx emission at full load condition. The corresponding NOx emission values of (PBD5\%W+100ppm, PBD10\%W+50ppm, PBD15\%W+100ppm, PBD20\%W+50ppm) are 128ppm,136ppm,74ppm,79ppm. at full load operating condition. The reason behind reduced NOx emission, It is the presence of water which absorbs heat to evaporate there by bringing down the peak temperature of the flame with adding the nano powder NOx emissions are reduced with compare to diesel [20,21].

Figure 8 shows the variation of $\mathrm{HC}$ with engine load for diesel, PBD and PBD emulsions with nano additives are shown in Fig 8. Hydrocarbon emission of $7 \mathrm{ppm}$ for $3 \mathrm{~kg}$ load varies to $18 \mathrm{ppm}$ for full load condition of diesel. Incase of PBD varies from 4ppm at $3 \mathrm{~kg}$ load to $17 \mathrm{ppm}$ for full load condition. The corresponding NOx emission values of (PBD5\%W+100ppm, PBD10\%W+50ppm, PBD15\%W+100ppm, PBD20\%W+50ppm) are $12 \mathrm{ppm}, 13 \mathrm{ppm}, 11 \mathrm{ppm} 13 \mathrm{ppm}$.With adding the nano powder the $\mathrm{HC}$ emissions are decreased because of complete combustion of the fuel inside the cylinder [19].

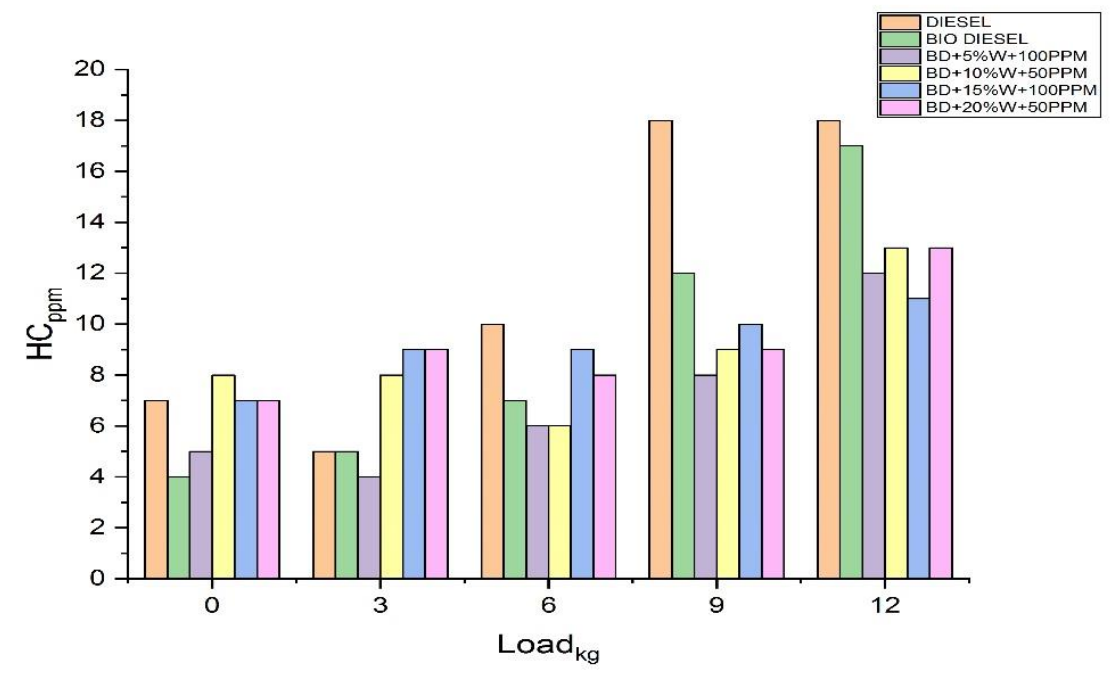

Figure 8. HC Vs Load for emulsified bio diesel addition of nano additives

Figure 9 shows the variation of $\mathrm{CO}_{2}$ emission with engine load. The $\mathrm{CO}_{2}$ emission increases with the engine load. At the partial loads almost all the nano-added tested fuels have given the same or lesser $\mathrm{CO}_{2}$ emissions compared to pure diesel. With addition of nano particles $\mathrm{CO}_{2}$ emission decreased compare to diesel. Because of complete combustion of the fuel inside the cylinder. 


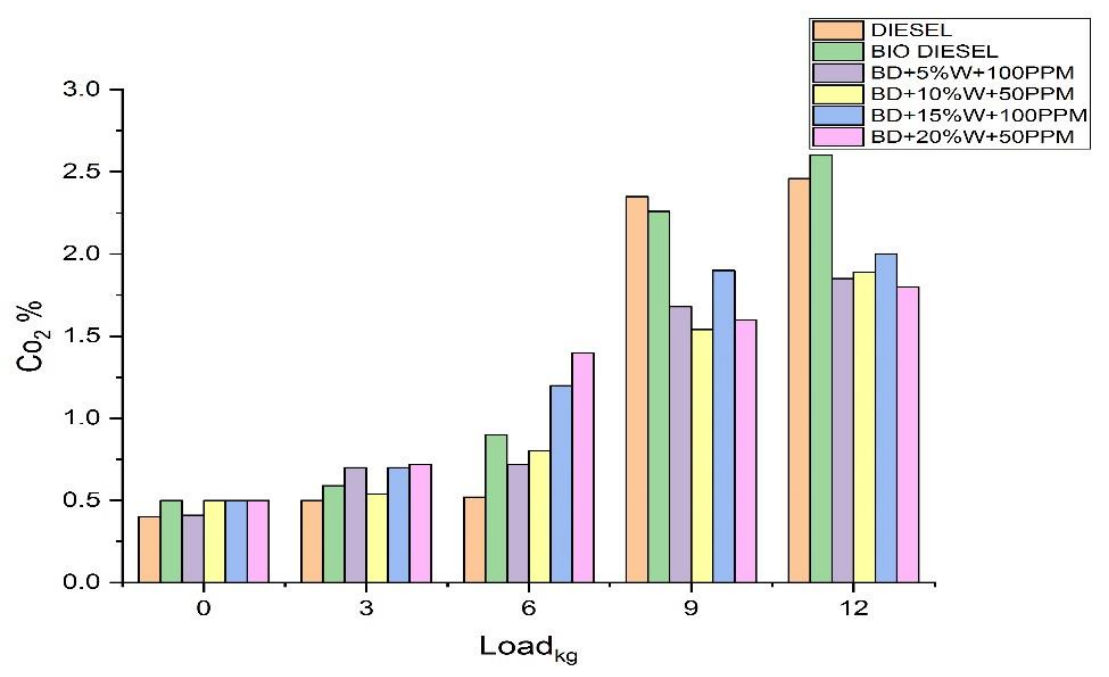

Figure 9. $\mathrm{CO}_{2}$ Vs Load emulsified bio diesel addition of nano additives

Figure10 shows the variation of $\mathrm{CO}$ emission. The $\mathrm{CO}$ emission increases with the engine load. Carbon monoxide is emitted as a result of incomplete combustion of carbon and oxygen under high temperature inside the cylinder. At full load condition diesel having $0.038 \% \mathrm{CO}$ and the bio diesel contains lower CO compare to diesel 0.027\%. And (PBD5\%W+100ppm, PBD10\%W+50ppm,PBD15\%W+100ppm,PBD20\%W+50ppm)produces0.022\%,0.021\%,0. $04 \%, 0.036 \%$.With adding the nano powder the $\mathrm{CO}$ emissions are same as diesel and slightly decreased for PBD5\%W+100PPM , PBD10\%W+50PPM because of complete combustion of the fuel inside the cylinder.

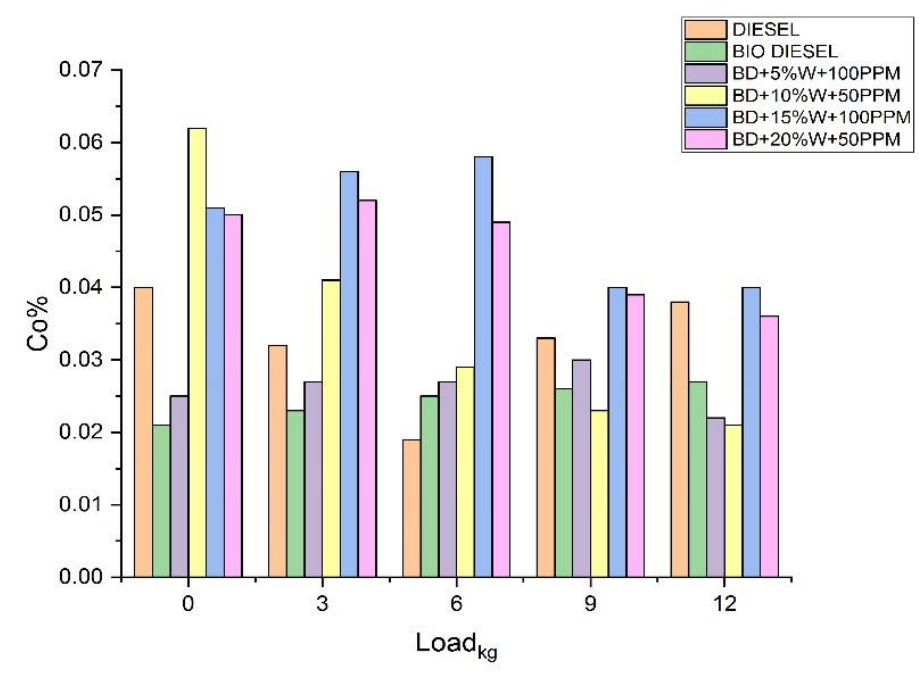

Figure 10. CO Vs Load emulsified bio diesel addition of nano additives 


\section{CONCLUSIONS}

The performance and emission characteristics of a single cylinder diesel engine with various proportions of cerium oxide nano particles in different blends of biodiesel are investigated. The effects of cerium oxide nano particle additive in diesel biodiesel blends are analyzed. The following major conclusions are arrived from the analysis of experimental investigations: The BTE increases for PBD20\%W+50 ppm and PBD+15\%W+100ppm aluminium oxide by $3 \%$ to $4 \%$ when comparing with the diesel. The SFC reduces by $1.72 \%$ with addition of ppm ALUMINA to PBD+15\%W+100ppm. The NOx emissions of PBD20\%W+50 ppm fuel are lower by $35-40 \mathrm{ppm}$ at maximum loads compared to diesel. The $\mathrm{CO}$ and $\mathrm{HC}$ emissions are same as diesel and slightly decreased for nano added emulsified biodiesel because of complete combustion of the fuel inside the cylinder.

\section{REFERENCES}

[1] Ali O.M, Mamat R, Faizal C.K, Review of effects of additives on biodiesel Properties, performance and emissions features, Journal of renewable and sustainable Energy. 2013; Volume-5.

[2] Meher L.C, Sagar D.V, Naik S.N, Technical aspects of biodiesel production by transesterification a review, Renewable and Sustainable Energy Reviews 2006; 10(3):248-268.

[3] Guru M, Koca A, Can O, Çınar C, Sahin F, Biodiesel production from waste chicken fat based sources and evaluation with $\mathrm{Mg}$ based additive in a diesel engine, Renewable Energy2010; 35(3): 637-643.

[4] Chen Y.H, Boyu. H, Tsung-Han. C, Tang. T, Fuel properties of microalgae oil biodiesel and its blends with petroleum diesel, Fuel.2012 (94):270-273.

[5] Ali O.M, Mamat R, Faizal C.K.M. Palm biodiesel production, properties and Fuel Additives. International Review of Mechanical Engineering, 2012; Vol-6; pp - 1573 $-1580$.

[6] Mohd Hafizil, Yasin M, Mamat R, Sharma K.V and Ahmad Fitri Yusop. Influence of Palm methyl ester (PME) as an alternative fuel in multi cylinder diesel engine. Journal of Mechanical Engineering and Sciences 2012; Volume 3: pp.331- 339.

[7] Yasin M.H.M, Mamat R, Aziz A, Yusop A. F and Ali M.H, Investigation on Combustion parameters of palm biodiesel operating with a diesel engine. Journal of Mechanical Engineering and Sciences 2015; Volume 9: pp. 1714-1726.

[8] Babu R. V, Sendilvelan S, Reduction of pollutants in CI engine using emulsion fuels to Reduce overall traffic-induced emissions. Global Journal of Research Engineering .2011;11(2): ISSN: 0975-5861.

[9] Basha J. S, Anand R, Role of nano additive blended biodiesel emulsion fuel on the Working characteristics of a diesel engine. Journal of Renewable and Sustainable Energy.2011; Vol-3.

[10] Abu-Zaid M, Performance of single cylinder, direct injection Diesel engine using water fuel emulsions. Energy Conversion and Management. 2004; vol. 45; 697-705. 
[11] Fayyad S. M, Abu. S, Al-Marahleh. G, Al-Momani. W, Al-Momani. M, Abulghanam. $\mathrm{Z}$, Badran $\mathrm{O}$ and Abu-Rahmah $\mathrm{T}$, Experimental emulsified diesel and benzene Investigation Research journal of applied sciences, Engineering and technology, 2011;2(3):268-273.

[12] Subramanian K. A, A comparison of water-diesel emulsion and timed injection of water into the intake manifold of a diesel engine for simultaneous control of NO and smoke emissions, Energy Conversion and Management 2011; 52:849- 857.

[13] Lif A, Holmberg K, Water-in-diesel emulsions and related systems. Advances inColloid and Interface Science 2006; 123-126, 231-239.

[14] Ozsezen A, Canakci N, Turkcan M, A and Sain C, Performance and combustion characteristics of a DI diesel engine fueled with waste palm oil and canola oil methyl esters, Fuel 2009;88(4):629-636.

[15] Qi D. H, Chen H, Geng L.M and Bian Y. Z. H, Experimental studies on the Combustion characteristics and performance of a direct injection engine fuelled with biodiesel / diesel blends. Energy Conversion and Management 2010; 51(12):29852992.

[16] Subramaniaman D, Murugesan A, Avinash A, Kumaravel A, Bio-diesel production and its engine characteristics. Renewable and Sustainable Energy Reviews 2013; 22: 361-370.

[17] Bo-JhihLin, Wei-HsinChen, WojciechM, Budzianowski, Cheng- TingHsieh, PeiHsunLin, Emulsification analysis of bio-oil and diesel under various combinations of emulsifiers. Applied Energy. 2016; 178:746-757.

[18] Cherng-Yuan Lin, Shiou-An Lin, Effects of emulsification variables on fuel properties of two- and three-phase biodiesel emulsions. Fuel 2007; 86; 210-217.

[19] Shaafi T, Velraj R, Influence of alumina nanoparticles, ethanol and isopropanol blend as additive with diesel soybean biodiesel blend fuel: Combustion, engine performance and emissions, Renewable Energy.2015; 80:655-663.

[20] Yanan Gan, Li Qiao, Combustion characteristics of fuel droplets with addition of nano and micron-sized aluminum particles Combustion and Flame.2011; 158:354-368.

[21] Srinivasa Rao M, Anand R.B, Performance and emission characteristics improvement Studies on a biodiesel fuelled DICI engine using water and $\mathrm{AlO}(\mathrm{OH})$ nanoparticles. Applied Thermal Engineering. 2015; 98:636-645. 